\title{
On the Variation With Flux and Frequency of the Core Loss Coefficients in Electrical Machines
}

\author{
Dan M. Ionel, Senior Member, IEEE, Mircea Popescu, Senior Member, IEEE, Stephen J. Dellinger, \\ T. J. E. Miller, Fellow, IEEE, Robert J. Heideman, and Malcolm I. McGilp
}

\begin{abstract}
A model of core losses, in which the hysteresis coefficients are variable with the frequency and induction (flux density) and the eddy-current and excess loss coefficients are variable only with the induction, is proposed. A procedure for identifying the model coefficients from multifrequency Epstein tests is described, and examples are provided for three typical grades of non-grainoriented laminated steel suitable for electric motor manufacturing. Over a wide range of frequencies between $20-400 \mathrm{~Hz}$ and inductions from 0.05 to $2 \mathrm{~T}$, the new model yielded much lower errors for the specific core losses than conventional models. The applicability of the model for electric machine analysis is also discussed, and examples from an interior permanent-magnet and an induction motor are included.
\end{abstract}

Index Terms-Brushless permanent-magnet (PM) motor, core loss, electric machine, Epstein test, finite-element analysis (FEA), induction motor, iron loss, laminated steel.

\section{INTRODUCTION}

$\mathbf{S}$ INCE its first formulation by Steinmetz more than a hundred years ago [1], the model of power losses in ferromagnetic materials has been continuously under study. Jordan brought a significant contribution by defining the hysteresis and eddy-current components [2] on which the analysis of electrical machines is still based. Improved models based on these concepts, e.g., [3] and [4], combined with careful calibration against experimental data collected from generic motor designs, have been typically used in industrial practice.

More recently, Bertotti proposed a frequency domain model including one supplementary term of excess or anomalous loss [5]. The model, which employs material-dependent constant coefficients, was further extended into the time domain [6], gained popularity in the electrical machines community, and was used in various forms in example studies, such as [7]-[9]. However, the general applicability of the model remained under scrutiny, and a new benchmark study, which

Paper IPCSD-05-112, presented at the 2005 IEEE International Electric Machines and Drives Conference, San Antonio, TX, May 15-18, and approved for publication in the IEEE TRANSACTIONS ON INDUSTRY APPLICATIONS by the Electric Machines Committee of the IEEE Industry Applications Society. Manuscript submitted for review July 1, 2005 and released for publication January 31, 2006.

D. M. Ionel and R. J. Heideman are with the Corporate Technology Center, A. O. Smith Corporation, Milwaukee, WI 53224-9512 USA (e-mail: dionel@aosmith.com; rheideman@aosmith.com).

M. Popescu, T. J. E. Miller, and M. I. McGilp are with the SPEED Laboratory, Department of Electrical Engineering, University of Glasgow, Glasgow G12 8LT, U.K. (e-mail: mircea@elec.gla.ac.uk; t.miller@elec.gla.ac.uk; mal@elec.gla.ac.uk).

S. J. Dellinger is with the Electrical Products Company, A. O. Smith Corporation, Tipp City, OH 45371-1899 USA (e-mail: sdellinger@aosepc.com).

Digital Object Identifier 10.1109/TIA.2006.872941 was conducted by a large number of research groups in Japan, provided good correlation between a surface permanent-magnet (PM) brushless motor experimental data and computations performed with steel models that ignored the anomalous loss component [10]. In another recent paper, Boglietti et al. [11] investigated eight different materials at inductions between 0.6 and $1.7 \mathrm{~T}$ and frequencies between 10 and $150 \mathrm{~Hz}$, systematically identified a zero value for the excess loss coefficient, and observed that, based on Epstein frame experiments, the individual contributions of eddy-current and anomalous losses cannot be separated. In yet another relevant paper, Chen and Pillay proposed a model with invariable coefficients for the eddy-current and excess loss and variable hysteresis loss parameters [12], an approach that combined and extended the concepts introduced by Hendershot and Miller [3], Bertotti [5], Slemon and Liu [13], and Miller et al. [14].

This paper brings further original contributions to the subject by studying three different laminated steels for electric motors on a wide range of frequencies between 20 and $400 \mathrm{~Hz}$ and inductions from 0.05 to $2 \mathrm{~T}$. A mathematical model fitting procedure, which results in the coefficients of the core loss components being variable with frequency and/or induction, is introduced and proved to yield relatively small errors between the numerical estimations and the Epstein measurements. The comparison between the improved model and a conventional model provides interesting insights into the separation of core loss components. Also included are two example studies from a prototype interior permanent-magnet (IPM) machine and an induction motor.

\section{EPSTEIn Frame MeAsurements}

One of the materials considered in this paper is a widely available generic M43 fully processed electric steel. The other two materials are varieties of semiprocessed cold-rolled electric steel, which after annealing have the main characteristics listed in Table I and will be denoted as SPA and SPB. All three are non-grain-oriented steel alloys and are suitable for the highvolume production of rotating electrical machines.

Samples of the materials were tested in an Epstein frame, which was built according to ASTM standard [15]. The excitation and measurement system was provided by a Brockhaus Messtechnik MPG100D $3 \mathrm{~Hz}$ to $1 \mathrm{kHz}$ ac/dc hysteresisgraph equipped with an amplifier rated at peak values of $40 \mathrm{~A}$ and $110 \mathrm{~V}$ [16]. The repeatability of the hysteresisgraph is certified by the instrument manufacturer at $0.1 \%$ for magnetic field measurements and $0.2 \%$ for power loss measurements. 
TABLE I

Main Characteristics of Sample Materials

\begin{tabular}{ccccc}
\hline $\begin{array}{c}\text { Material } \\
\text { type }\end{array}$ & Thickness & $\begin{array}{c}\text { Permeability } \\
\text { at } 1.5 \mathrm{~T} \text { and } 60 \mathrm{~Hz}\end{array}$ & $\begin{array}{c}\text { Loss } \\
\text { at } 1.5 \mathrm{~T} \text { and } 60 \mathrm{~Hz}\end{array}$ & Density \\
\hline & {$[\mathrm{in}]$} & {$[-]$} & {$[\mathrm{W} / \mathrm{lb}]$} & {$\left[\mathrm{kg} / \mathrm{m}^{3}\right]$} \\
\hline SPA & 0.020 & 2137 & 2.29 & 7800 \\
SPB & 0.022 & 3071 & 3.16 & 7850 \\
M43 & 0.018 & 1387 & 1.88 & 7700 \\
\hline
\end{tabular}

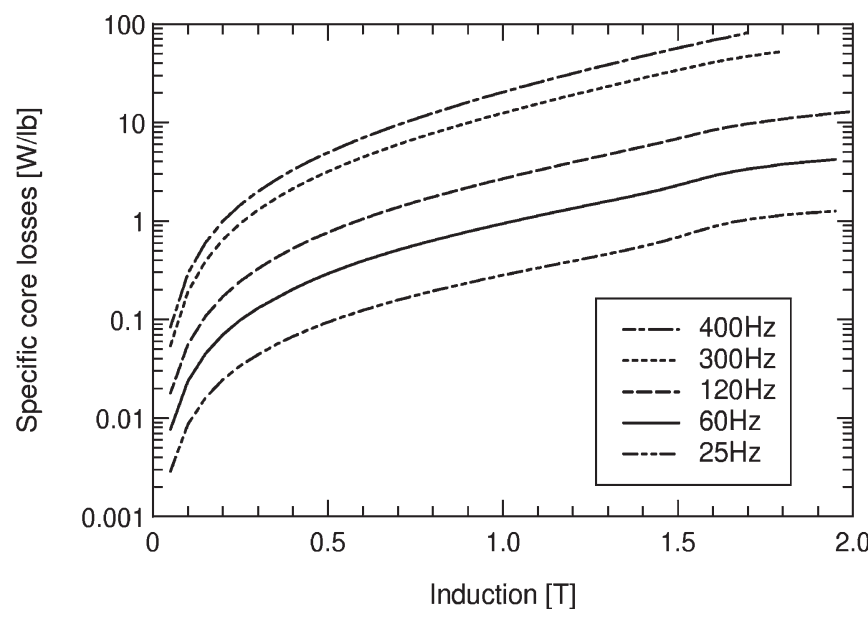

Fig. 1. Core losses measured in an Epstein frame on a 1sample of SPA (semiprocessed electric steel of type A).

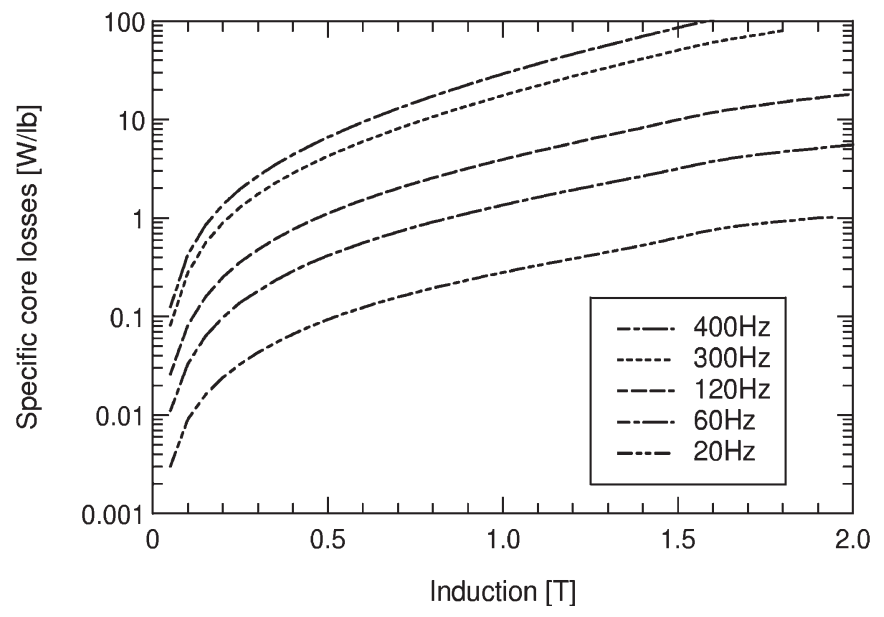

Fig. 2. Core losses measured in an Epstein frame on a sample of SPB (semiprocessed electric steel of type B).

Magnetic permeability and core loss measurements (Figs. 1-3) were performed over a wide range of frequencies in induction increments of $0.05 \mathrm{~T}$, according to an experimental procedure suggested in [17]. (The terminology of core loss, rather than iron loss, and induction, rather than flux density, follows the relevant ASTM standards [15].)

\section{New Model for Specific Core Losses}

Under sinusoidal alternating excitation, which is typical for form-factor-controlled Epstein frame measurements, the specific core losses $w_{\mathrm{Fe}}$ in watts per pound (or watts per kilogram) can be expressed by

$$
w_{\mathrm{Fe}}=k_{h} f B^{\alpha}+k_{e} f^{2} B^{2}+k_{a} f^{1.5} B^{1.5}
$$

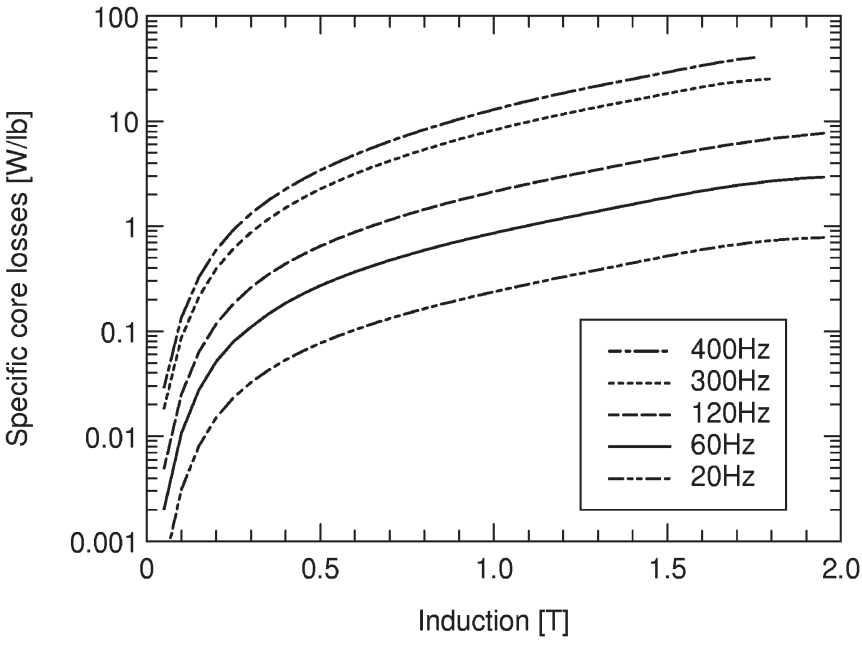

Fig. 3. Core losses measured in an Epstein frame on a sample of M43 fully processed electric steel.

where the first right-hand term stands for the hysteresis loss component and the second for the eddy-current loss component. The last term corresponds to the excess or anomalous loss component, which is influenced by intricate phenomena, such as microstructural interactions, magnetic anisotropy, nonhomogenous locally induced eddy currents. Despite the complicated physical background and based on a statistical study, Bertotti has proposed the simple expression for the excess losses, similar to that of the eddy-current losses, but with an exponent value of 1.5 [5]. In a conventional model, the values of the coefficients $k_{h}, \alpha, k_{e}$, and $k_{a}$ are assumed to be constants, which are invariable with frequency $f$ and induction $B$.

As the first step of the procedure developed in order to identify the values of the coefficients, (1) is divided by the frequency resulting in

$$
\frac{w_{\mathrm{Fe}}}{f}=a+b \sqrt{f}+c(\sqrt{f})^{2}
$$

where

$$
a=k_{h} B^{\alpha} \quad b=k_{a} B^{1.5} \quad c=k_{e} B^{2} .
$$

For any induction $B$ at which measurements were taken, the coefficients of the aforementioned polynomial in $\sqrt{f}$ can be calculated by quadratic fitting based on a minimum of three points (Fig. 4). During trials, it was observed that a sample of five points, represented by measurements at the same induction and different frequencies, is beneficial in improving the overall stability of the numerical procedure. In this paper, measurements at one low frequency of $25 \mathrm{~Hz}$ (or $20 \mathrm{~Hz}$ ), three intermediate frequencies of 60,120 , and $300 \mathrm{~Hz}$, and one high frequency of $400 \mathrm{~Hz}$ were used where available (Figs. 1-3), and, typically, the values of the fitting residual for (2) were very close to unity, i.e., $r^{2} \approx 1$, indicating a very good approximation.

From (2) and (3), the eddy-current coefficient $k_{e}$ and the excess loss coefficient $k_{a}$ are readily identifiable. These coefficients are independent of frequency, but, unlike those for the conventional model, they exhibit a significant variation 


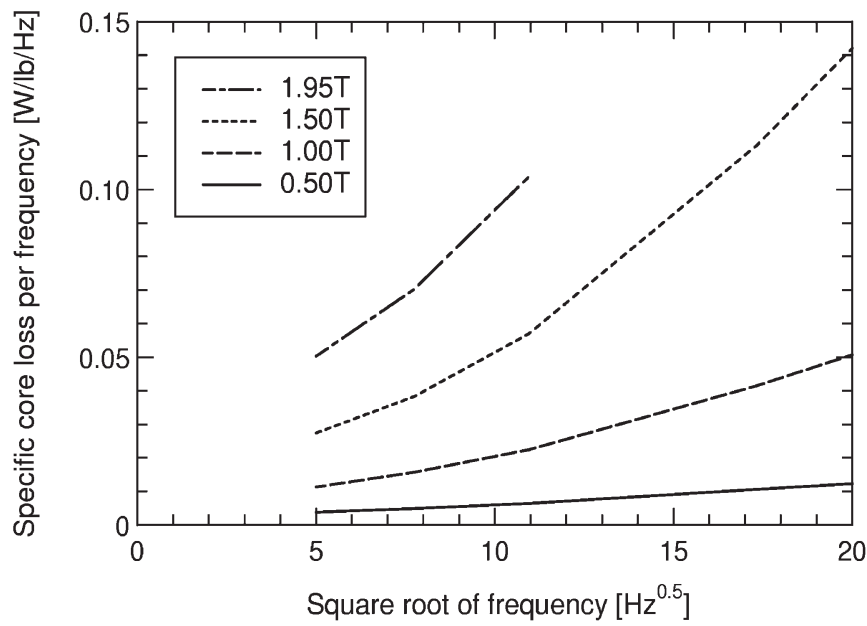

Fig. 4. Ratio of core loss and frequency $w_{\mathrm{Fe}} / f$, as a function of $\sqrt{f}$ according to (2), for SPA steel.

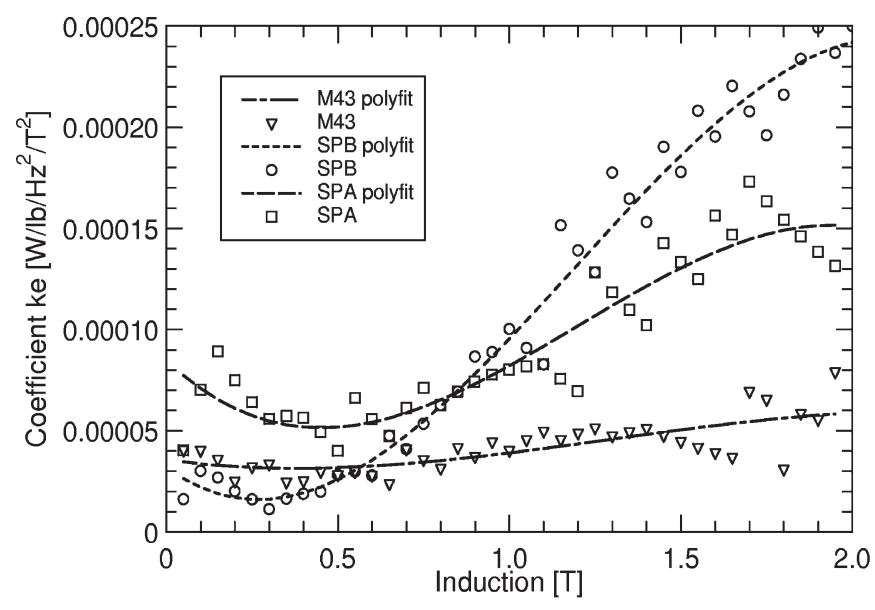

Fig. 5. Variation of the eddy-current loss component coefficient $k_{e}$ with magnetic induction; $k_{e}$ is invariable with frequency.

with the induction (Figs. 5 and 6). The following third-order polynomials were employed for curve fitting of $k_{e}$ and $k_{a}$ :

$$
\begin{aligned}
& k_{e}=k_{e 0}+k_{e 1} B+k_{e 2} B^{2}+k_{e 3} B^{3} \\
& k_{a}=k_{a 0}+k_{a 1} B+k_{a 2} B^{2}+k_{a 3} B^{3} .
\end{aligned}
$$

For $k_{e}$, the best $r^{2}$ was obtained for SPB with a value of 0.98 , followed by SPA at 0.87 and M43 at 0.75 . For $k_{a}, r^{2}$ varied from 0.883 for M43 to 0.82 for SPB and down to 0.78 for SPA. The discrete variations of $k_{e}$ and $k_{a}$ at high induction are noticeable in Figs. 5 and 6, and these could be attributed, at least in part, to the fact that less than five fitting points were available for fitting (2). The use of a lower order polynomial in (4) and (5) is not recommended, as it leads to a poorer data fit with a considerably lower $r^{2}$.

One possible explanation for the variation of $k_{e}$ and $k_{a}$ with induction - the two coefficients having somehow complementary trends (see Figs. 5 and 6), i.e., $k_{e}$ substantially increasing and $k_{a}$ substantially decreasing with $B$, respectively, after $k_{e}$ has experienced a minimum value in the range of $0.3-0.5 \mathrm{~T}$ and $k_{a}$ a local maximum around $0.5-0.7 \mathrm{~T}$-could lay in the 1.5 fixed exponent value of the anomalous loss component and/or

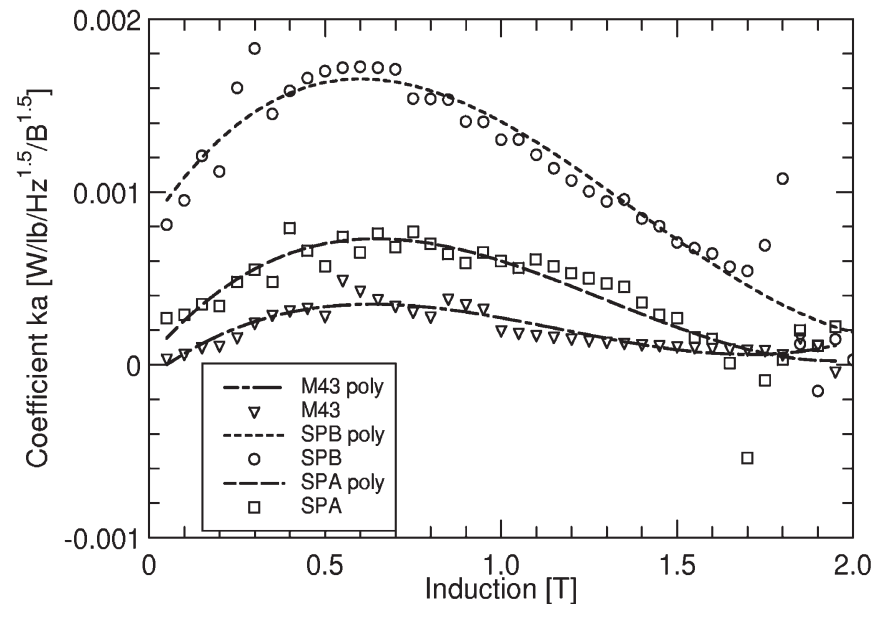

Fig. 6. Variation of the excess (anomalous) loss component $k_{a}$ with magnetic induction; $k_{a}$ is invariable with frequency.

in the fact that the separation in-between the eddy-current and anomalous losses is questionable, this being a hypothesis already advanced by other authors [11] based on a different analysis than ours. On the other hand, it should be mentioned that yet other authors [12], by following a similar frequency separation procedure as per (2) and (3), were able to identify constant valued coefficients $k_{e}$ and $k_{a}$-a result that we have not experienced on any of the three steels reported in this paper or on any other steels that we have studied.

In order to identify the coefficients $k_{h}$ and $\alpha$, which can be traced back to Steinmetz's original formula, further assumptions have to be made regarding their variation. An improved model, in which $\alpha$ is a first-order polynomial of flux density, has already been in use for a number of years in a commercially available motor design software [4]. Recently, in [12], a secondorder polynomial has been proposed for $\alpha$, and in our new formulation, the following third-order polynomial is employed:

$$
\alpha=\alpha_{0}+\alpha_{1} B+\alpha_{2} B^{2}+\alpha_{3} B^{3} .
$$

Substituting (6) in (3) and applying a logarithmic operator leads to an equation

$$
\log a=\log k_{h}+\left(\alpha_{0}+\alpha_{1} B+\alpha_{2} B^{2}+\alpha_{3} B^{3}\right) \log B
$$

with five unknowns, namely $k_{h}$ and the four polynomial coefficients of $\alpha$. The coefficient $a$ represents the ratio of hysteresis loss and frequency, which is calculated from (2) by substituting the values of $b$ and $c$ from (3) and making use of the analytical estimators (4) and (5), which greatly reduce numerical instabilities. The plot of $\log a$ against induction at a set frequency indicates three intervals of different variation types, which, for the example shown in Fig. 7, can be approximately set to induction ranges of $0.0-0.7,0.7-1.4$, and $1.4-2 \mathrm{~T}$. For a given frequency and induction range, (7) is solved by linear regression using at least five induction values, i.e., $\log B$. The discrete values of the hysteresis loss coefficient $k_{h}$ and the average values $\bar{\alpha}$ for the three materials studied are listed in Tables II-IV.

It is interesting to note that the aspect of the $\log a$ curves plotted in Fig. 7 also provides support to an observation made 


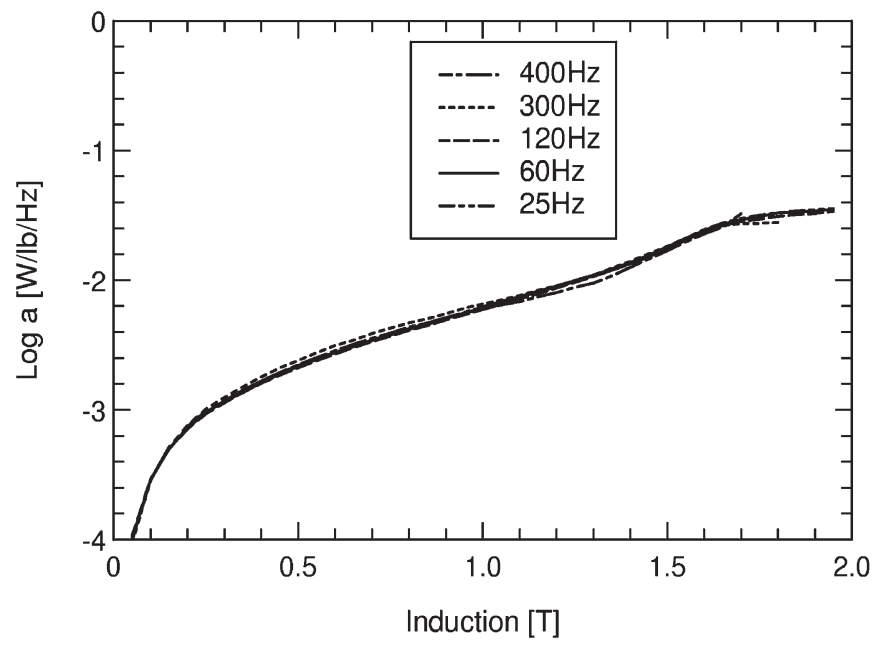

Fig. 7. Logarithm of the ratio of hysteresis loss and frequency for SPA steel; curves for different frequencies are overlapping.

TABLE II

HYSTERESIS LOSS COEFFICIENTS FOR SPA STEEL

\begin{tabular}{cccc}
\hline $\begin{array}{c}\text { Induction } \\
{[\mathrm{T}]}\end{array}$ & $\begin{array}{c}\text { Frequency } \\
{[\mathrm{Hz}]}\end{array}$ & $\begin{array}{c}k_{h} \\
{\left[\mathrm{~W} / \mathrm{lb} / \mathrm{Hz} / \mathrm{T}^{\alpha}\right]}\end{array}$ & $\begin{array}{c}\bar{\alpha} \\
{[-]}\end{array}$ \\
\hline & 25 & 0.0036 & 0.7995 \\
$B<0.7$ & 60 & 0.0026 & 0.3932 \\
& 120 & 0.0035 & 0.7839 \\
& 300 & 0.0028 & 0.3650 \\
& 400 & 0.0022 & 0.1543 \\
\hline & 25 & 0.0061 & 1.9085 \\
$0.7<B<1.4$ & 60 & 0.0061 & 1.9412 \\
& 120 & 0.0060 & 1.9438 \\
& 300 & 0.0065 & 1.7218 \\
& 400 & 0.0060 & 1.5924 \\
\hline & 25 & 0.0329 & -0.4379 \\
$B>1.4$ & 60 & 0.0368 & -0.6895 \\
& 120 & 0.0349 & -0.6411 \\
& 300 & 0.0247 & -0.1990 \\
& 400 & 0.0210 & -0.0840 \\
\hline
\end{tabular}

TABLE III

HYSTERESIS LOSS COEFFICIENTS FOR SPB STEEL

\begin{tabular}{cccc}
\hline $\begin{array}{c}\text { Induction } \\
{[\mathrm{T}]}\end{array}$ & $\begin{array}{c}\text { Frequency } \\
{[\mathrm{Hz}]}\end{array}$ & $\begin{array}{c}k_{h} \\
{\left[\mathrm{~W} / \mathrm{lb} / \mathrm{Hz} / \mathrm{T}^{\alpha}\right]}\end{array}$ & $\begin{array}{c}\bar{\alpha} \\
{[-]}\end{array}$ \\
\hline \multirow{5}{*}{$B<0.7$} & 20 & 0.0035 & 0.8776 \\
& 60 & 0.0021 & 0.2106 \\
& 120 & 0.0032 & 0.6674 \\
& 300 & 0.0015 & -0.2386 \\
& 400 & 0.0012 & -0.6309 \\
\hline \multirow{3}{*}{$<<1.4$} & 20 & 0.0058 & 2.4753 \\
& 60 & 0.0060 & 2.3988 \\
& 120 & 0.0059 & 2.4502 \\
& 300 & 0.0056 & 2.5882 \\
$B>1.4$ & 400 & 0.0064 & 2.2232 \\
\hline & 20 & 0.0117 & 1.2402 \\
& 60 & 0.0100 & 1.5328 \\
& 120 & 0.0063 & 2.5134 \\
& 300 & 0.0067 & 2.5971 \\
& 400 & 0.0062 & 2.8385 \\
\hline
\end{tabular}

by other authors in [10], where a two-step approximation of $k_{h}$ and $\alpha$ was proposed without the disclosure of any other details. In our model, an estimation with three induction steps is employed for $k_{h}$ and $\alpha$.

While other numerical models with some type of variable hysteresis coefficients have already been published, e.g., [3], [10], [12], and [14], a phenomenological theory to support such
TABLE IV

HYSTERESIS LOSS COEFFICIENTS FOR M43 STEEL

\begin{tabular}{cccc}
\hline $\begin{array}{c}\text { Induction } \\
{[\mathrm{T}]}\end{array}$ & $\begin{array}{c}\text { Frequency } \\
{[\mathrm{Hz}]}\end{array}$ & $\begin{array}{c}k_{h} \\
{\left[\mathrm{~W} / \mathrm{lb} / \mathrm{Hz} / \mathrm{T}^{\alpha}\right]}\end{array}$ & $\begin{array}{c}\bar{\alpha} \\
{[-]}\end{array}$ \\
\hline & 20 & 0.0066 & 1.2184 \\
$B<0.7$ & 60 & 0.0053 & 0.9518 \\
& 120 & 0.0101 & 1.7305 \\
& 300 & 0.0131 & 2.0347 \\
& 400 & 0.0135 & 2.1005 \\
\hline & 20 & 0.0099 & 1.8648 \\
$0.7<B<1.4$ & 60 & 0.0099 & 1.8906 \\
& 120 & 0.0102 & 1.9086 \\
& 300 & 0.0110 & 1.9821 \\
& 400 & 0.0113 & 2.0656 \\
\hline & 20 & 0.0161 & 1.0681 \\
$B>1.4$ & 60 & 0.0105 & 1.9251 \\
& 120 & 0.0110 & 1.8642 \\
& 300 & 0.0095 & 2.1767 \\
& 400 & 0.0071 & 2.9065 \\
\hline & & &
\end{tabular}

a mathematical formulation is not yet unanimously accepted. One possible explanation can lay in the fact that the area of the quasi-static magnetization loop, which is a measure of the hysteresis losses, is influenced by the dynamic losses [5], [6] and that the instability of the magnetic domains at the microscopic level is a nonlinear and complicated function of magnetization and frequency.

Based on the measurement of core losses $w_{\mathrm{Fe}}$ at different inductions $B_{k}$ and frequencies $f_{i}$, the calculation of the eddy currents, $k_{e}$, excess, $k_{a}$, and hysteresis, $k_{h}$ and $\alpha$, coefficients is summarized by the following computational procedure:

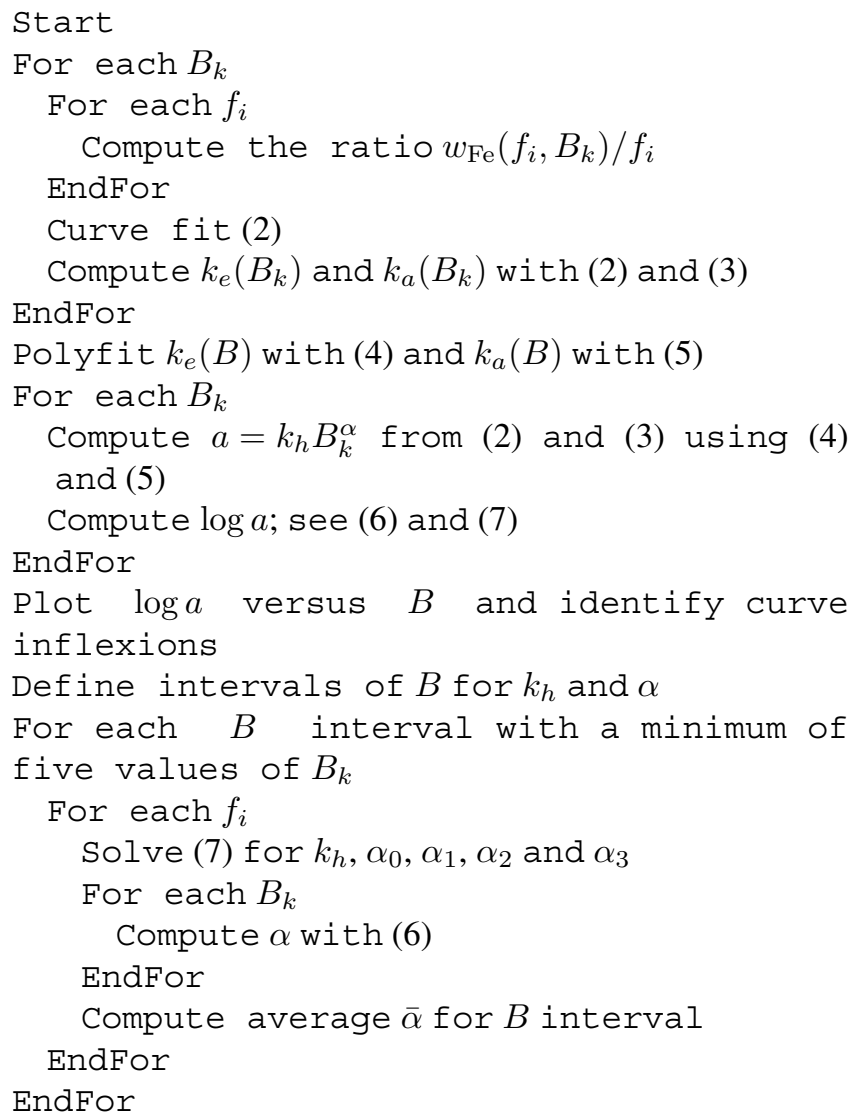




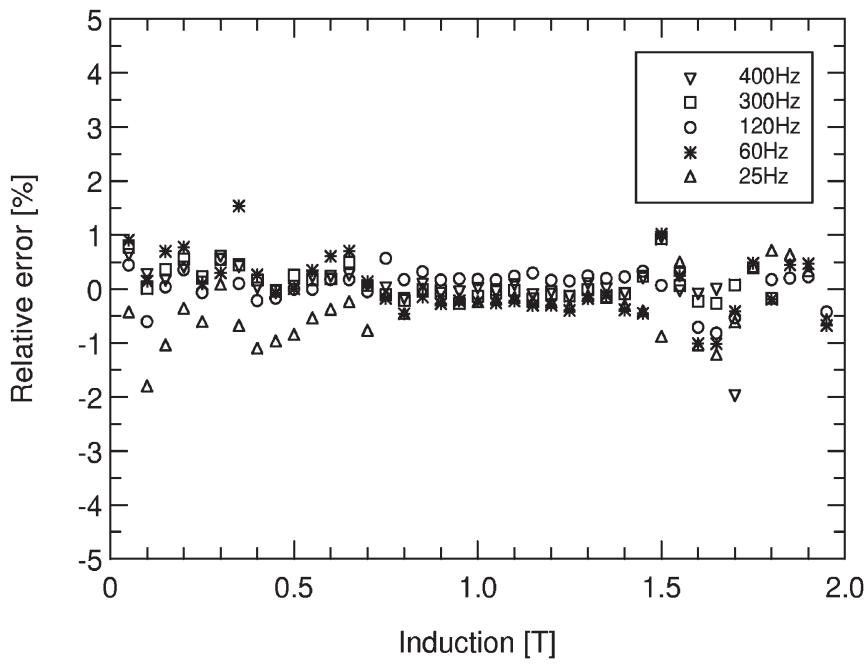

Fig. 8. Relative error between the calculated and the Epstein measured core loss at the frequencies used in the numerical model fitting for SPA steel.

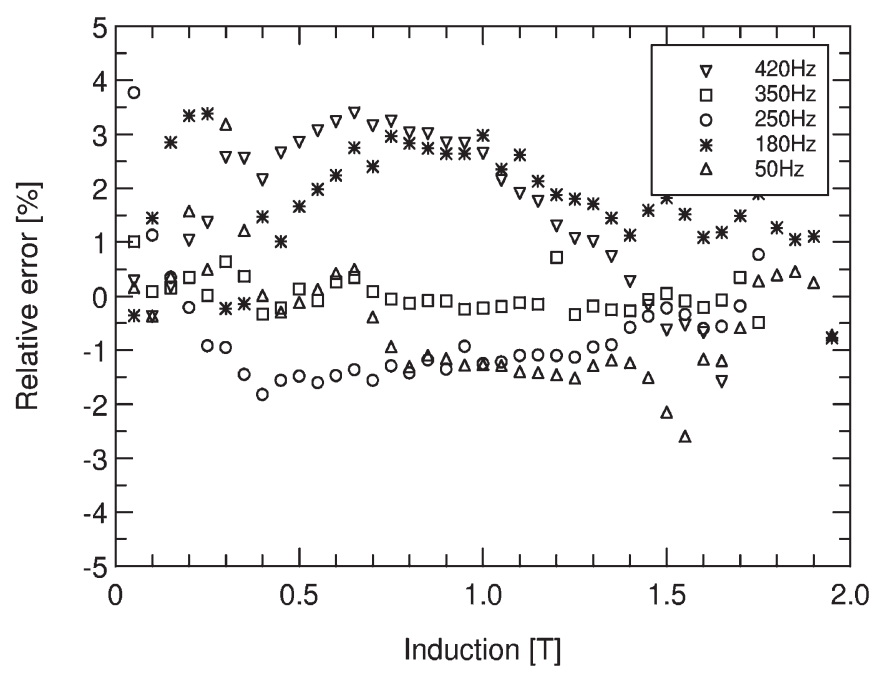

Fig. 9. Relative error between the calculated and the Epstein measured core loss at frequencies not used in the numerical model fitting for SPA steel.

The new core loss model covers frequencies up to $400 \mathrm{~Hz}$ and a very wide induction range between 0.05 and $2 \mathrm{~T}$, and yet, the relative error between the estimated and measured specific core losses is very low, as shown in Fig. 8 for SPA steel. The results in Fig. 8 were produced using the actual value of $\alpha$ at each set $B$, as per (6). The errors for the SPB and M43 steel, which are not included here for brevity, are even lower.

The model was also used to estimate losses at frequencies not employed in the curve-fitting procedure, and an example is provided in Fig. 9. In this case, analytically fitted values, as per (4) and (5), were used for $k_{e}$ and $k_{a}$, and linearly interpolated values from Tables II-IV were employed for $k_{h}$ and average $\bar{\alpha}$. The errors are still well within limits considered satisfactory for most practical engineering applications and considerably lower than those provided by other known models, which represents, in our opinion, a remarkable result.

\section{Comparison With Conventional Models}

The comparison of the new model with the conventional model provides some interesting observations and, most

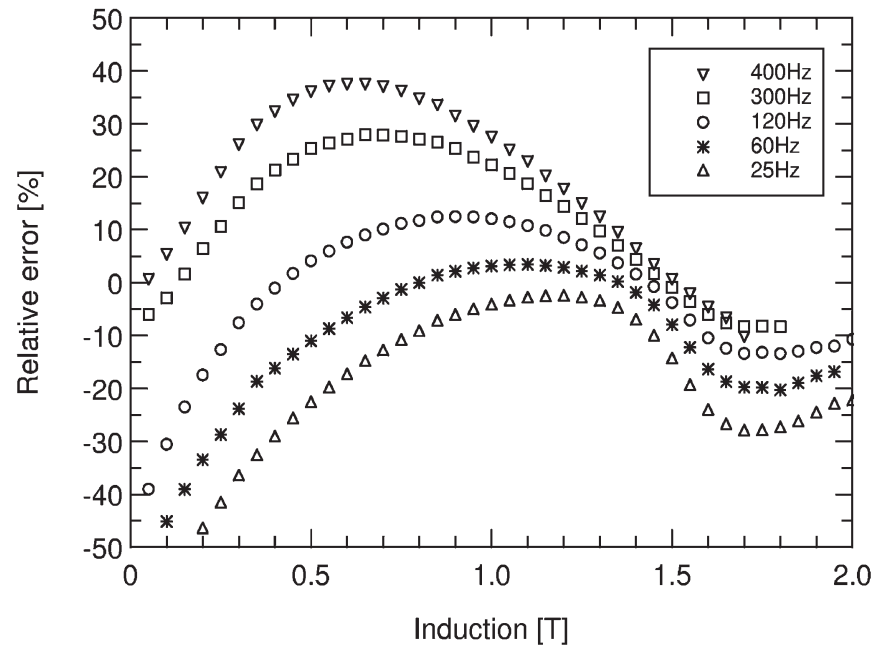

Fig. 10. Relative error between the values estimated by a conventional model with constant coefficients and Epstein measured core losses for SPA steel. The $y$-axis scale limits are ten times larger than in Figs. 8 and 9.

notably, shows that the new model can be regarded as an extension of the classical theory rather than a contradiction of it. For example, conventional values for the power coefficient $\alpha$ from the hysteresis loss formula are typically in the range of 1.6-2.2 T. In Tables II-IV, with the new coefficient values, this approximately corresponds to low frequencies and midrange inductions.

According to conventional models, the eddy-current loss, which is often referred as "classical" loss, can be estimated with a constant value coefficient calculated as

$$
k_{e}=\frac{\pi^{2} \sigma \delta^{2}}{6 \rho_{v}}
$$

based on the electrical conductivity $\sigma$, the lamination thickness $\delta$, and the volumetric mass density $\rho_{V}$. For the materials considered, SPA, SPB, and M43, the classical values of $k_{e}$ correspond on the nonlinear curves shown in Fig. 5 to an induction of approximately $1.3,1.5$, and $1.7 \mathrm{~T}$, respectively. Analytical estimations or typical values are not available for $k_{h}$ and $k_{a}$.

As a comparative exercise, coefficient values were selected to be constant, for the hysteresis losses equal to the values corresponding to $60 \mathrm{~Hz}$ and the $0.7-1.4 \mathrm{~T}$ range (see Table II) and for the eddy-current and excess losses equal to the values at $1.5 \mathrm{~T}$ (see Figs. 5 and 6), i.e., the actual values for the SPA steel are $k_{h}=0.0061 \mathrm{~W} / \mathrm{lb} / \mathrm{Hz} / \mathrm{T}^{\alpha}$, where $\alpha=1.9412, k_{e}=1.3334 \times 10^{-4} \mathrm{~W} / \mathrm{lb} / \mathrm{Hz}^{2} / \mathrm{T}^{2}$, and $k_{a}=$ $2.7221 \times 10^{-4} \mathrm{~W} / \mathrm{lb} / \mathrm{Hz}^{1.5} / \mathrm{T}^{1.5}$. In this case, the very large errors and the numerical oscillations, which fall around the selected reference point of $1.5 \mathrm{~T}$, exemplified in Fig. 10, are not a surprise and are in line with previous studies published by other authors, e.g., [10].

Selecting different but constant values for the four coefficients may change the induction around which the errors oscillate and even reduce the maximum error but will not be able to bring this within acceptable limits for a wide range of frequencies and inductions due to the inherent limitations 


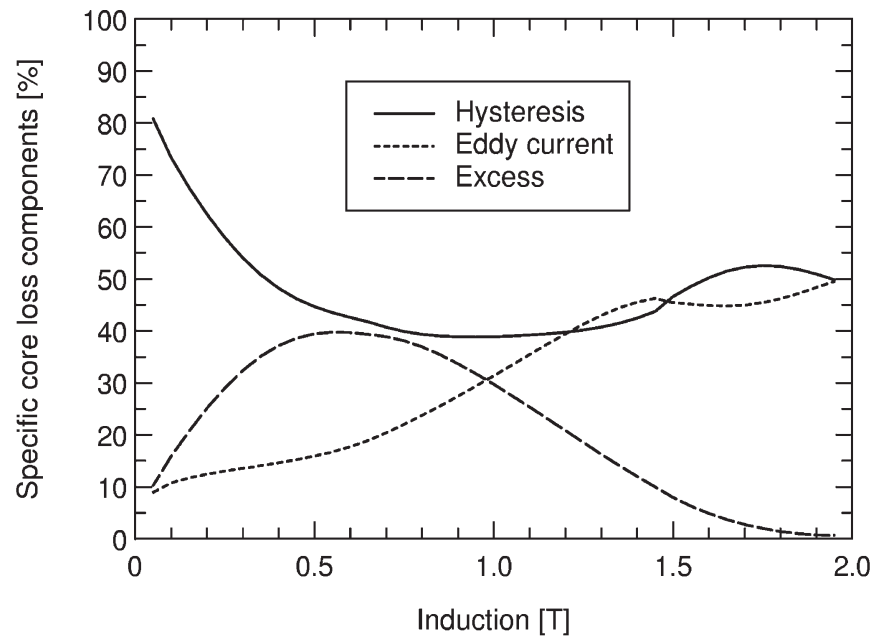

Fig. 11. Separation of core loss components at $60 \mathrm{~Hz}$ according to the new model for SPA steel.

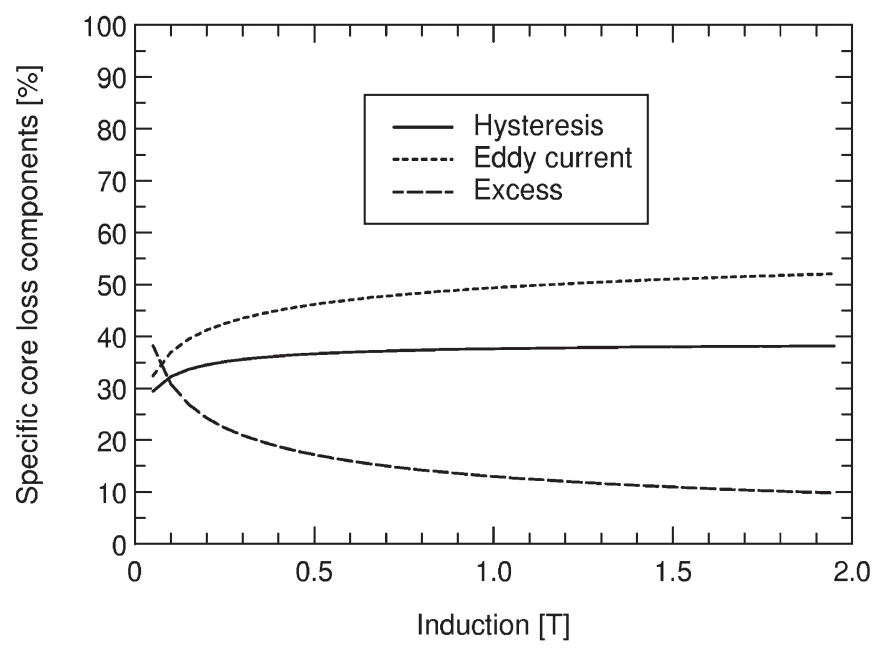

Fig. 12. Separation of core loss components at $60 \mathrm{~Hz}$ according to a conventional model for SPA steel.

built in the conventional model. On the other hand, reliable steel models are vital, for example, for cost-competitive linefed induction motor designs, in which the magnetic loading is pushed to the very limits, and for variable-speed machines, in which the flux is weakened at high-speed operation. Therefore, accurate information of core losses at low flux density but high frequency is essential.

The error values in Figs. 8 and 9 on one hand and Fig. 10 on the other hand are in sharp contrast, and they are plotted on a different $y$-axis scale, which clearly illustrates the advantages of employing third-order polynomials for $k_{e}, k_{a}$, and $\alpha$, together with three induction steps for $\alpha$ and $k_{h}$. The use of a second- or first-order polynomial would increase the error, "transitioning" the fit from the good results shown in Figs. 8 and 9 toward a typically poorer conventional fit as shown in Fig. 10. Oscillating errors as those illustrated in Fig. 10 also provide an interesting explanation as to why, sometimes, the calculations employing a conventional model with constant coefficients are not entirely out of proportion; provided that the flux density around which the error oscillations occur is corresponding to an "average"

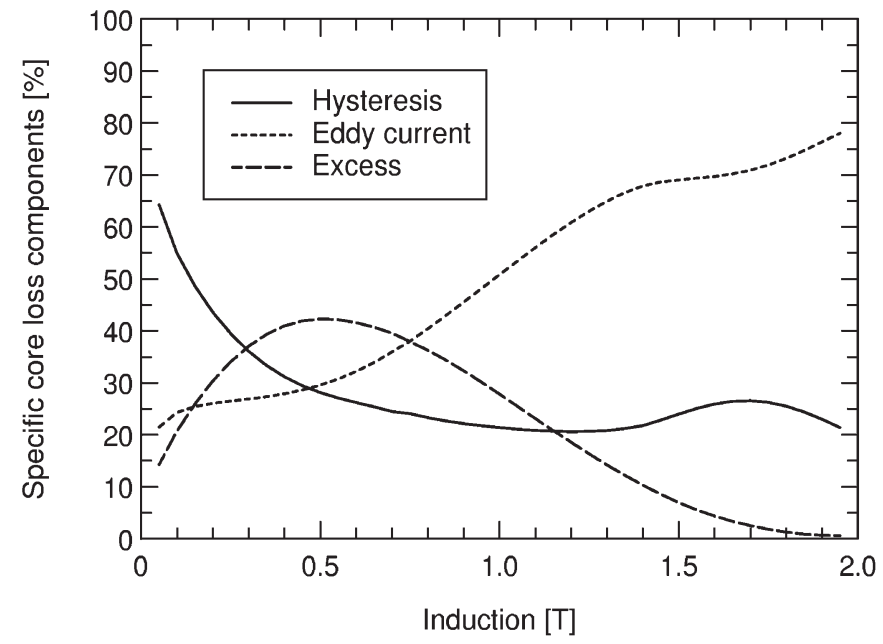

Fig. 13. Separation of core loss components at $180 \mathrm{~Hz}$ according to the new model for SPA steel.

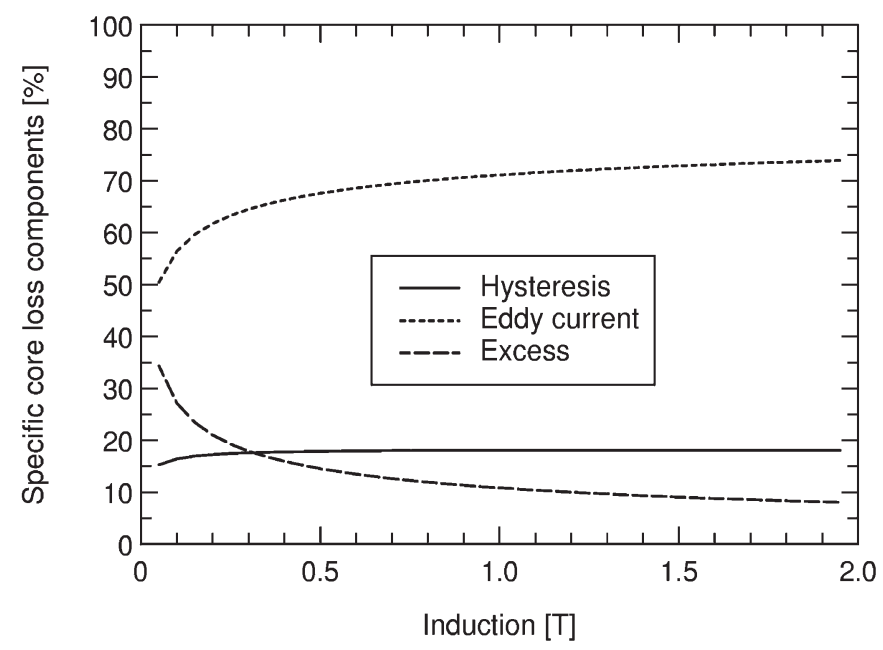

Fig. 14. Separation of core loss components at $180 \mathrm{~Hz}$ according to a conventional model for SPA steel.

operating point of the magnetic circuit, overall, the overestimation and the underestimation for different regions of the core will tend to cancel each other through a more or less fortunate arrangement.

Inasmuch as the numerical validity of the new specific core loss model is based on a systematic mathematical algorithm to identify coefficients and is proven through the small errors to measurements, its phenomenological aspects are open to debate. In particular, the separation in hysteresis, on one hand, and eddy-current and excess losses, on the other hand, is of great interest, as each of these components receives a different treatment in electrical machine analysis, which will be discussed in the next section. At $60 \mathrm{~Hz}$ and midrange inductions of $0.7-1.4 \mathrm{~T}$, the percentage of hysteresis out of the total core losses is relatively constant, and the values calculated by the new and the conventional model are even comparable (Figs. 11 and 12). However, the values can be largely different at other frequencies (Figs. 13 and 14) and/or inductions, a situation that can have direct consequences on the accuracy with which electric motors are modeled. 


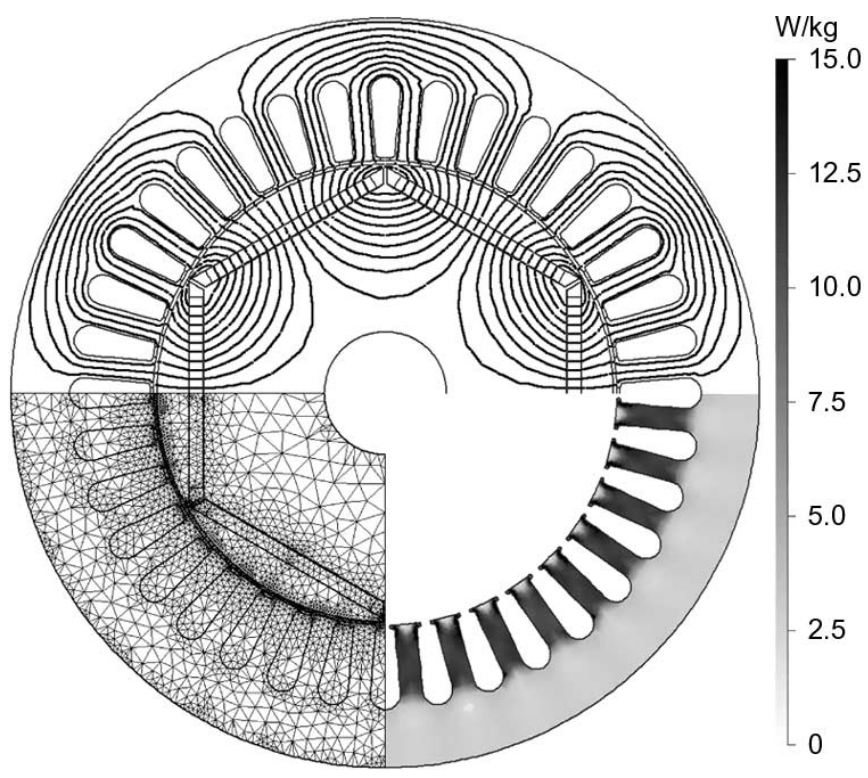

Fig. 15. FE model of a six-pole IPM machine with the distribution of specific core losses shown in shades of gray on a watt-per-kilogram scale.

\section{Calculation of Core Losses in ELECTRICAL MACHINES}

The conversion from the frequency domain to the time domain of a nonlinear model, such as (1), which is based on data collected from a standard Epstein sample excited with a sinusoidally form-factor-controlled alternating magnetic field is not straightforward, especially if the coefficients are variable. Therefore, Fourier harmonic analysis, under the assumption that the contribution of the fundamental frequency is largely dominant, is the preferred engineering choice for machine simulation at steady-state operation. The following equations calculate the eddy-current and anomalous specific core losses at any point in the magnetic circuit by adding the individual contribution of each $n$th harmonic along the radial and tangential directions:

$$
\begin{aligned}
& w_{e}=\sum_{n=1}^{\infty} k_{e n}(n f)^{2}\left(B_{r, n}^{2}+B_{t, n}^{2}\right) \\
& w_{a}=\sum_{n=1}^{\infty} k_{a n}(n f)^{1.5}\left(B_{r, n}^{1.5}+B_{t, n}^{1.5}\right) .
\end{aligned}
$$

The hysteresis losses, on the other hand, are only dependent of the fundamental frequency $f$ and the peak value of the waveform of flux density $B$ and therefore have no high harmonic contributions. The hysteresis loss is affected though by a correction factor due to the minor hysteresis loops [18].

The open-circuit core losses in the stator core of a threephase six-pole 184-frame prototype IPM machine with $\mathrm{NdFeB}$ magnets and a magnetic circuit made of SPA steel were calculated with a finite-element analysis (FEA) software [19] and the previously described core loss models (Fig. 15). As mentioned before, the method can be employed for the simulation of any steady-state operation of an electrical machine, and the

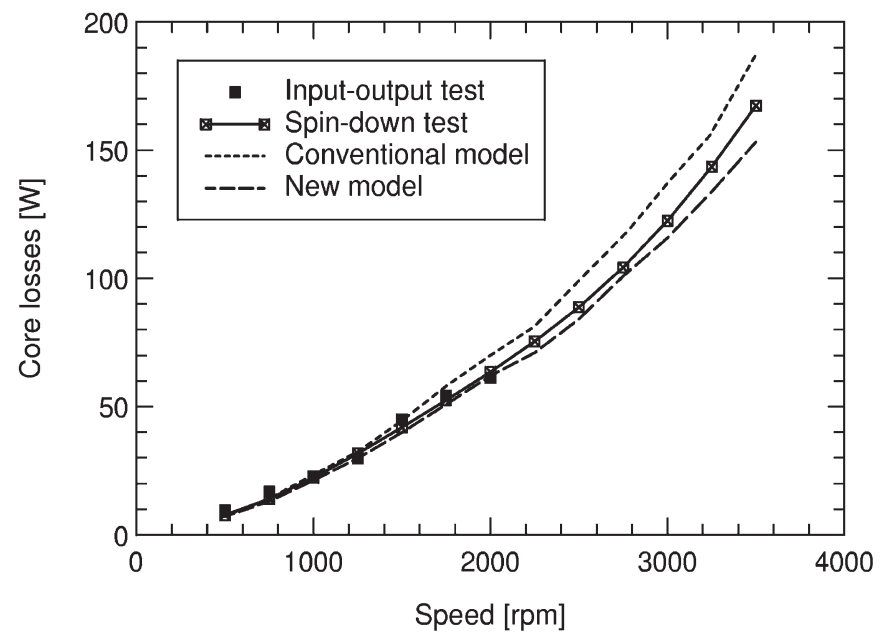

Fig. 16. Computed and measured open-circuit losses in the IPM machine.

open-circuit condition of the IPM was a preferred choice for numerical validation, because, in this case, the flux density in the magnetic circuit is basically independent of frequency (speed), which is determined by the PM flux, allowing the case study to concentrate on the variation of core losses with frequency only. Furthermore, in the open-circuit simulation, other unknowns, such as the phase current waveforms, are eliminated. The flux density waveforms in various parts of the stator core were decomposed in Fourier series, and the harmonic contributions up to the 11th order were added. For harmonics with a frequency exceeding $400 \mathrm{~Hz}$, the coefficients used where those determined for $400 \mathrm{~Hz}$.

The comparison of computational results shown in Fig. 16, obtained with the new mathematical model, for the losses in the stator core only and data from spin-down and input-output experiments is considered satisfactory, taking into account the inherent errors of such motor tests [10], the inclusion-in the experimental data only - of a small component of rotor losses due to high-order harmonics of the magnetic field, and the additional losses caused by the mechanical stress introduced by frame fitting [10] and/or lamination punching, even if largely successful stress relief was provided through annealing [20]. Furthermore, the flux density in the back iron, which accounts for approximately a third of the total stator core loss, is partially exposed to rotational flux with rather significant radial and tangential components (Fig. 17), which can produce rotational core losses [21]. On the other hand, the losses calculated with a conventional core loss model having constant parameters systematically overestimated the experimental data.

Similar FE computations were performed for the no-load operation of a 3-phase 2-pole 101-frame induction motor design (Fig. 18). This operating condition, under variable voltage supply, was the preferred choice for numerical validation, because the case study can concentrate on the variation of core losses with flux density only and additional unknowns such as the rotor bar current distribution are eliminated. Prototypes built from the two steels SPB and M43 were tested at quasisynchronous speed with the power input-power output method. In deeming as satisfactory the numerical results of Fig. 19, consideration was given to the fact that the experimentally 


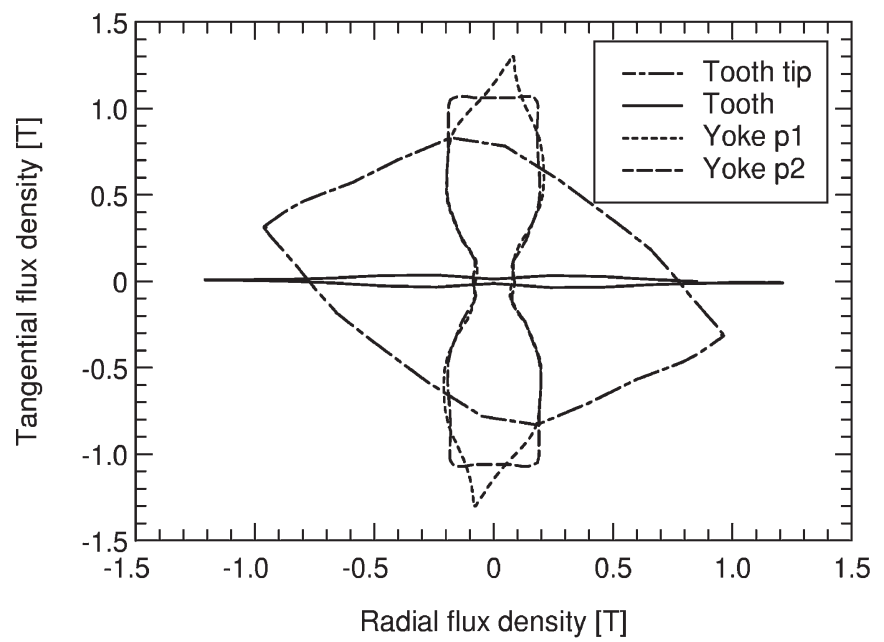

Fig. 17. Loci of magnetic flux density in the stator core of the IPM machine with two points $p_{1}$ and $p_{2}$ exemplifed for the yoke.

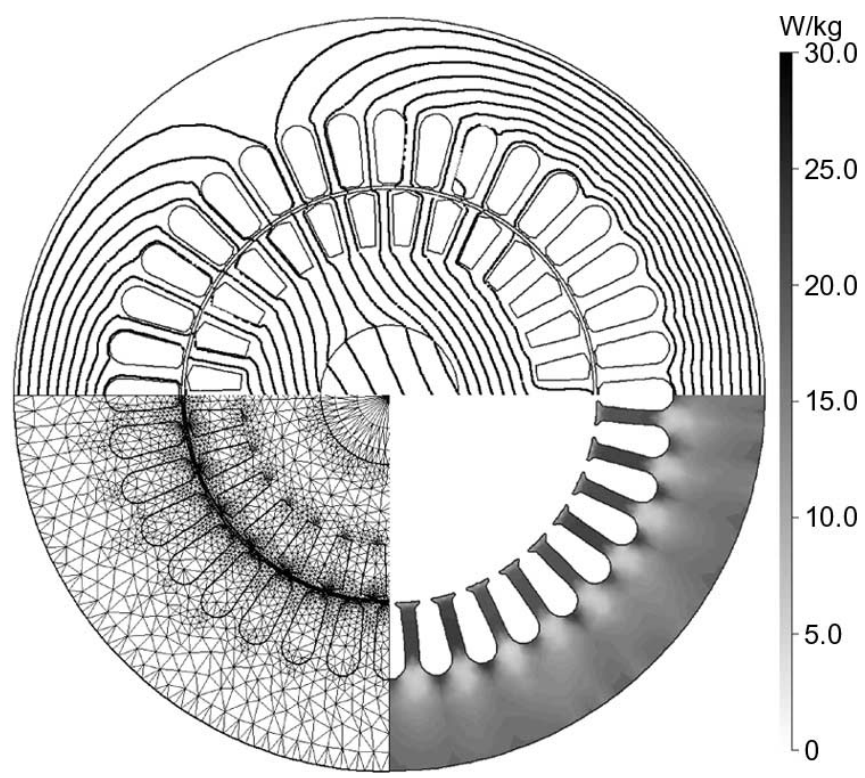

Fig. 18. FE model of a two-pole induction motor with the distribution of specific core losses shown in shades of gray on a watt-per-kilogram scale.

separated total core losses include a small component of rotor losses due to high-order harmonics of the magnetic field, whereas the FEA calculations are for the stator core only. Furthermore, a significant fact is that the back iron, which contributes by more than $70 \%$ to the total stator core losses, is exposed to rotational magnetic flux (Fig. 20). The detailed analysis of this phenomenon is beyond the scope of a model based on the summation of core losses due to two orthogonal alternating magnetic field components, as in (9) and (10), and employing material coefficients derived from unidirectional magnetic field Epstein tests. An extra challenge to the modeling effort is brought about by the fact that the prototype is designed to run, at rated voltage and above, with the magnetic circuit very strongly saturated, especially in the teeth, as shown in Fig. 20, where the example tooth flux density basically overlaps the radial axis.

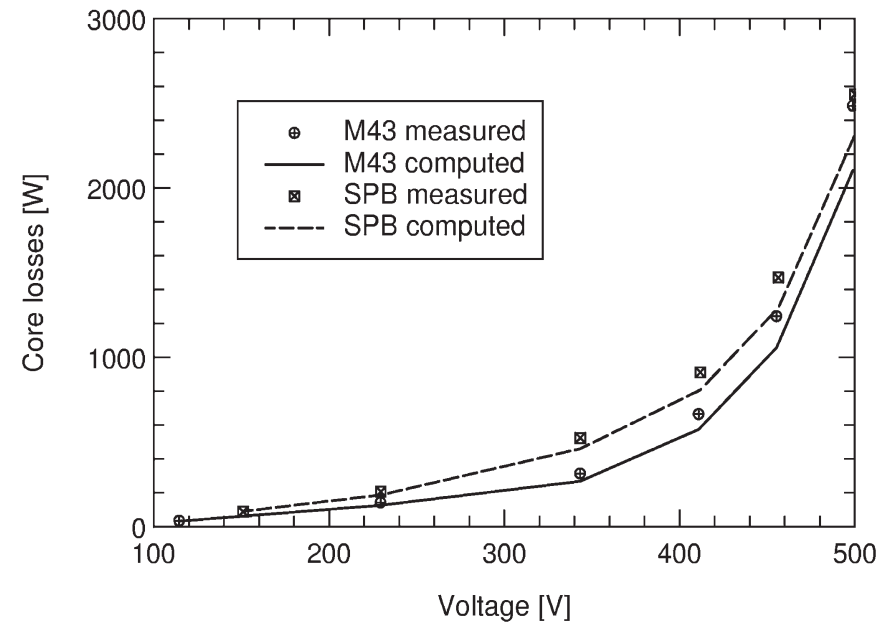

Fig. 19. Computed and measured no-load core losses in the induction motor Protoypes were built with two different steels.

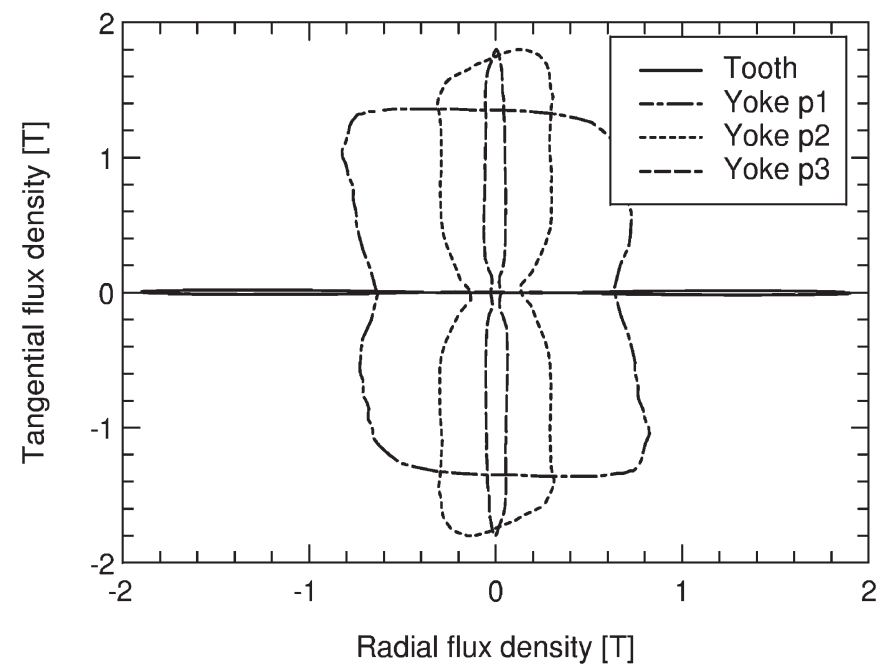

Fig. 20. Loci of magnetic flux density in the stator core of the induction motor with three points $p_{1}, p_{2}$, and $p_{3}$ exemplifed for the yoke.

\section{CONCLUSION}

The proposed model uses hysteresis loss coefficients, which are variable with frequency and induction, and eddy-current and excess loss coefficients, which are variable with induction only, and overcomes the inaccuracies of the typical conventional core loss models with constant coefficients. For the three grades of laminated electric steel studied, the errors between the computations with the new model and Epstein frame measurements are very low over a wide range of frequency between 20 and $400 \mathrm{~Hz}$ and a wide range of induction from as low as $0.05 \mathrm{~T}$ to as high as $2 \mathrm{~T}$. A comparative study has illustrated the limitations of the conventional model and its restricted applicability to $60-\mathrm{Hz}$ line frequency and midlevel induction in an approximate range of $0.7-1.4 \mathrm{~T}$.

The model with variable coefficients also provides a different perspective onto the component separation of the specific core losses, having a direct influence on electric machine analysis. Inasmuch as the application of the model in the daily industrial practice has to surpass the extra hurdles of collecting a 
substantial amount of material data, which is required by the numerical procedures of coefficient identification, and of FEA usage, that is recommended in order to obtain accurate local information on the electromagnetic field, the application of the model for research and development looks promising, especially in the light of the results obtained on two case studies from an IPM machine and an induction motor.

\section{ACKNOWLEDGMENT}

The authors would like to thank the colleagues at A. O. Smith Corporation who participated in a project aimed at the better characterization of electric steel, especially C. Riviello and R. Bartos.

\section{REFERENCES}

[1] C. P. Steinmetz, "On the law of hysteresis (originally published in1892)," Proc. IEEE, vol. 72, no. 2, pp. 196-221, Feb. 1984.

[2] H. Jordan, "Die ferromagnetischen konstanten fur schwache wechselfelder," Elektr. Nach. Techn., 1924.

[3] J. R. Hendershot and T. J. E. Miller, Design of Brushless PermanentMagnet Motors. Mentor, OH: Magna Physics, 1994.

[4] T. J. E. Miller and M. I. McGilp, PC-BDC 6.5 for Windows-Software. Glasgow, U.K.: SPEED Laboratory, Univ. Glasgow, 2004.

[5] G. Bertotti, "General properties of power losses in soft ferromagnetic materials," IEEE Trans. Magn., vol. 24, no. 1, pp. 621-630, Jan. 1988.

[6] F. Fiorillo and A. Novikov, "An improved approach to power losses in magnetic laminations under nonsinusoidal induction waveform," IEEE Trans. Magn., vol. 26, no. 5, pp. 2904-2910, Sep. 1990.

[7] G. Bertotti, A. A. Boglietti, M. Chiampi, D. Chiarabaglio, and F. Fiorillo, "An improved estimation of iron loss in rotating electrical machines," IEEE Trans. Magn., vol. 27, no. 6, pp. 5007-5009, Nov. 1991.

[8] K. Atallah, Z. Q. Zhu, and D. Howe, "An improved method for predicting iron losses in brushless permanent magnet dc drives," IEEE Trans. Magn., vol. 28, no. 5, pp. 2997-2999, Sep. 1992.

[9] M. A. Mueller, S. Williamson, T. Flack, K. Atallah, B. Baholo, D. Howe, and P. Mellor, "Calculation of iron losses from time-stepped finite-element models of cage induction machines," in Conf. Rec. IEE EMD, Durham, U.K., Sep. 1995, pp. 88-92.

[10] H. Domeki, Y. Ishihara, C. Kaido, Y. Kawase, S. Kitamura, T. Shimomura, N. Takahashi, T. Yamada, and K. Yamazaki, "Investigation of benchmark model for estimating iron loss in rotating machine," IEEE Trans. Magn., vol. 40, no. 2, pp. 794-797, Mar. 2004.

[11] A. Boglietti, A. Cavagnino, M. Lazzari, and M. Pastorelli, "Predicting iron losses in soft magnetic materials with arbitrary voltage supply: An engineering approach," IEEE Trans. Magn., vol. 39, no. 2, pp. 981-989, Mar. 2003.

[12] Y. Chen and P. Pillay, "An improved formula for lamination core loss calculations in machines operating with high frequency and high flux density excitation," in Proc. IEEE 37th IAS Annu. Meeting, Pittsburgh, PA, Oct. 2002, pp. 759-766.

[13] G. Slemon and X. Liu, "Core losses in permanent magnet motors," IEEE Trans. Magn., vol. 26, no. 5, pp. 1653-1655, Sep. 1990.

[14] T. J. E. Miller, D. Staton, and M. I. McGilp, "High-speed PC based CAD for motor drives," in Proc. Power Elect. EPE, Brighton, U.K., 1993, pp. 435-439.

[15] Standard Test Method for Alternating-Current Magnetic Properties of Materials at Power Frequencies Using Wattmeter-Ammeter-Voltmeter Method and 25-cm Epstein Test Frame, ASTM A343/A343M-03, 2003.

[16] MPG100D AC/DC Hysteresisgraph-User Manual, Brockhaus Messtechnik, Ludenscheid, Germany, 2002.

[17] K. E. Blazek and C. Riviello, "New magnetic parameters to characterize cold-rolled motor lamination steels and predict motor performance," IEEE Trans. Magn., vol. 40, no. 4, pp. 1833-1838, Jul. 2004.

[18] J. D. Lavers, P. Biringer, and H. H. Hollitscher, "A simple method of estimating the minor loop hysteresis loss in thin laminations," IEEE Trans. Magn., vol. MAG-14, no. 5, pp. 386-388, Sep. 1978.

[19] T. J. E. Miller and M. I. McGilp, PC-FEA 5.0 for Windows-Software. Glasgow, U.K.: SPEED Laboratory, Univ. Glasgow, 2002.
[20] A. Smith and K. Edey, "Influence of manufacturing processes on iron losses," in Conf. Rec. IEE EMD, Durham, U.K., Sep. 1995, pp. 77-81.

[21] C. A. Hernandez-Aramburo, T. C. Green, and A. C. Smith, "Estimating rotational iron losses in an induction machine," IEEE Trans. Magn., vol. 39, no. 6, pp. 3527-3533, Nov. 2003.

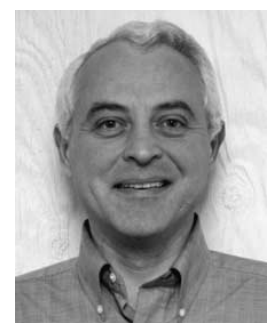

Dan M. Ionel (M'91-SM'01) received the M.Eng. and $\mathrm{Ph} . \mathrm{D}$. degrees in electrical engineering from the Polytechnic University of Bucharest, Bucharest, Romania.

Since 2001, he has been a Principal Electromagnetic Engineer with the Corporate Technology Center, A. O. Smith Corporation, Milwaukee, WI. He began his career with the Research Institute for Electrical Machines (ICPE-ME), Bucharest, Romania, and continued in the U.K., where he worked for the SPEED Laboratory, Department of Electrical Engineering, University of Glasgow, and then for the Brook Crompton Company, Huddersfield, U.K. His previous professional experience also includes a oneyear Leverhulme visiting fellowship at the University of Bath, Bath, U.K.

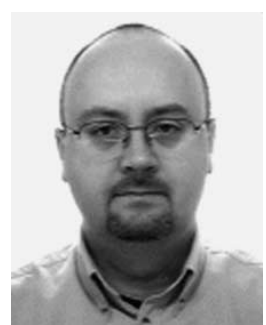

Mircea Popescu (M'98-SM'04) was born in Bucharest, Romania. He received the M.Eng. and $\mathrm{Ph} . \mathrm{D}$. degrees from the University "Politehnica" Bucharest, Bucharest, Romania, in 1984 and 1999, respectively, and the D.Sc. degree from Helsinki University of Technology, Espoo, Finland, in 2004, all in electrical engineering.

From 1984 to 1997, he was involved in industrial research and development at the Research Institute for Electrical Machines (ICPE-ME), Bucharest, Romania, as a Project Manager. From 1991 to 1997 , he cooperated as a Visiting Assistant Professor with the Electrical Drives and Machines Department, University "Politehnica" Bucharest. From 1997 to 2000, he was a Research Scientist with the Electromechanics Laboratory, Helsinki University of Technology. Since 2000, he has been a Research Associate with the SPEED Laboratory, University of Glasgow, Glasgow, U.K.

Dr. Popescu was the recipient of the 2002 First Prize Paper Award from the Electric Machines Committee of the IEEE Industry Applications Society.

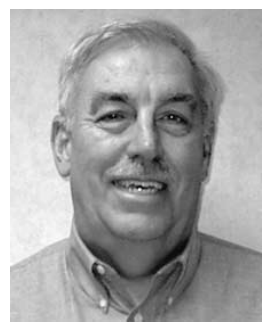

Stephen J. Dellinger received the B.Sc. and M.Sc. degrees in electrical engineering from the University of Dayton, Dayton, $\mathrm{OH}$

$\mathrm{He}$ is currently the Director of Engineering with the Electric Products Company, A. O. Smith Corporation, Tipp City, OH. His responsibilities include the development and introduction to manufacturing of new motor technologies. He has been with A. O. Smith Corporation for almost 40 years and, during this time, he has held various positions in manufacturing, engineering, and management.

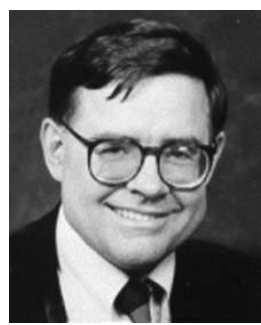

T. J. E. Miller (M'74-SM'82-F'96) is a native of Wigan, U.K. He received the B.Sc. degree from the University of Glasgow, Glasgow, U.K., and Ph.D. degree from the University of Leeds, Leeds. U.K.

$\mathrm{He}$ is Professor of Electrical Power Engineering and founder and Director of the SPEED Consortium at the University of Glasgow, U.K. He is the author of over 100 publications in the fields of motors, drives, power systems, and power electronics, including seven books. From 1979 to 1986, he was an Electrical Engineer and Program Manager at GE Research and Development, Schenectady, NY, and his industrial experience includes periods with GEC (U.K.), British Gas, International Research and Development, and a student apprenticeship with Tube Investments Ltd.

Prof. Miller is a Fellow of the Institution of Electrical Engineers, U.K. 


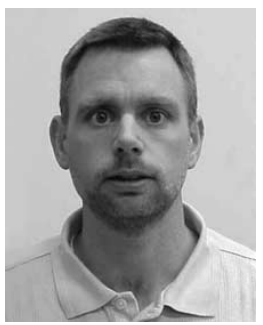

Robert J. Heideman received the B.S. degree from the University of Wisconsin, Madison, and the M.S. degree from Purdue University, West Lafayette, IN, both in metallurgical engineering.

$\mathrm{He}$ is currently the Director of Materials and Processes at the Corporate Technology Center, A. O. Smith Corporation, Milwaukee, WI, and is responsible for projects for both A. O. Smith Electrical and Water Product Companies. During his career, he has also worked for the Kohler Company, Kohler, WI, Tower Automotive, Milwaukee, WI, and Delco Electronics (now Delphi), Kokomo, IN.

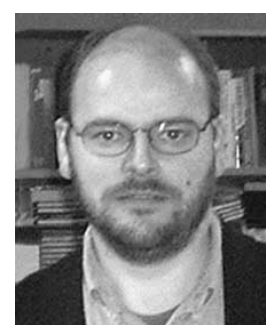

Malcolm I. McGilp was born in Helensburgh, U.K., in 1965. He received the B.Eng.(Hons.) degree in electronic systems and microcomputer engineering from the University of Glasgow, Glasgow, U.K., in 1987.

Since graduating, he has been with the SPEED Laboratory, University of Glasgow, first as a Research Assistant from 1987 to 1996 and as a Research Associate since then. He is responsible for the software architecture of the SPEED motor design software and has developed the interface and user facilities that allow it to be easy to learn and integrate with other PC-based software. 